\title{
The effect of food intake on the pk of rhein released from diacerein
}

\author{
Ming Huang ${ }^{\circledR}$, Shun-lin Zong, Quan-ying Zhang* \\ Clinical Pharmacology Laboratory, The Second Affiliated Hospital of Soochow University, Suzhou, China
}

\begin{abstract}
Diacerein is a symptomatic slow-acting drug used for treating osteoarthritis. This drug is completely metabolized into the active metabolite rhein before reaching the systemic circulation. This study evaluated the effects of food on the pharmacokinetics of rhein released from diacerein in healthy Chinese subjects. This was a single-center, randomized, single-dose, open-label, two-period, cross-over study. Twentyfour healthy subjects were randomly selected to receive a single oral dose of $50 \mathrm{mg}$ diacerein capsule in either fasted or fed state on two separate visits. Plasma samples were analyzed with LC-MS/MS. Pharmacokinetic parameters were calculated using WinNonlin software. In the fasted and fed states, the main pharmacokinetic parameters of diacerein capsule were as follows: $C_{\max }$ were $(4471 \pm 936)$, $(3225 \pm 755) \mathrm{ng} / \mathrm{mL}, \mathrm{t}_{1 / 2}$ were $(4.22 \pm 0.42),(4.19 \pm 1.05) \mathrm{h}, \mathrm{t}_{\max }$ were $(2.61 \pm 1.25),(3.81 \pm 1.29) \mathrm{h}, \mathrm{AUC}_{0-24 \mathrm{~h}}$ were $(24223 \pm 4895),(24316 \pm 5856) \mathrm{h} \cdot \mathrm{ng} / \mathrm{mL}$, and $\mathrm{AUC}_{0-\infty}$ were $(24743 \pm 5046),(25170 \pm 6415) \mathrm{h} \cdot \mathrm{ng} / \mathrm{mL}$. The absorption rate of diacerein capsule was obviously delayed by food intake but the absorption degree remained unaffected.
\end{abstract}

Keywords: Diacerein capsule/pharmacokinetics. HPLC-MS/MS. High fat and calories diet.

\section{INTRODUCTION}

Diacerein is a symptomatic slow-acting drug for treating patients with osteoarthritis (SYSADOA). This drug is completely metabolized into the active metabolite rhein before reaching the systemic circulation. Rhein exerts anti-inflammatory properties through the inhibition of interleukin-1, a cytokine highly involved in the degenerative process of cartilage. Rhein stops the degeneration and stimulates regeneration of cartilage in long-term treatment of osteoarthritis.

The pharmacokinetic profile of diacerein in humans has been investigated in previous studies (Chakrabarty et al., 2008; Debord et al., 1993; Debord et al., 1994; Mandawgade et al., 2016; Nicolas et al., 1998). Diacerein is commercially available under the brand name of Artrodar ${ }^{\circledR}$. As shown in previous studies, and as indicated on the Artrodar ${ }^{\circledR}$ label, the maximum rhein plasma concentrations are achieved approximately 1.8-2.0 h after oral administration to fasting healthy volunteers. The absolute bioavailability is approximately $35 \%-65 \%$.

*Correspondence: Q.-y. Zhang. Clinical Pharmacology Laboratory, The Second Affiliated Hospital of Soochow University, NO.1055 Sanxiang Road, Suzhou, 215004, China. Tel.: +86512 67783687; fax: +8651267783686. E-mail: sdfeyyq@163.com
Approximately $99 \%$ of rhein is bound to plasma albumin and a lesser extent, to lipoproteins and $\gamma$ immunoglobulins. The elimination half-life of rhein from blood plasma $\left(\mathrm{t}_{1 / 2}\right)$ is approximately 5-7 h. Excretion is mainly renal as rhein and as conjugates of rhein (glucuronide and sulphate). Following an oral administration of 50-100 mg, dose of diacerein, approximately $50 \%$ of the total dose is recovered in the urine as rhein, and more than $90 \%$ as the sulpho- and gluco-conjugated forms of rhein.

This phase I clinical trial of diacerein capsule $\left(\right.$ Artrodar $^{\circledR}$ ) was performed at the Second Affiliated Hospital of Soochow University (Suzhou, China) in 2014. This study was conducted to evaluate the effects of food on pharmacokinetics of diacerein capsule $\left(\operatorname{Artrodar}^{\circledR}\right)$ in healthy Chinese subjects, and is the first report of its kind.

\section{MATERIAL AND METHOD}

\section{Drugs, chemical standards and reagents}

Diacerein capsules (Artrodar ${ }^{\circledR}$, Batch: 018, specifications: $50 \mathrm{mg} /$ capsules) provided by TRB Pharma S.A. Chemical standard of rhein (Batch: 110757-200206, purity $100.0 \%$ ) and emodin (internal standard, IS, Batch: 110756-200110, purity $100.0 \%$ ) were provided by 
National Institutes for Food and Drug Control. HPLCgrade methanol were purchased from Merck.K GaA. ARgrade formic acid and ammonium acetate were purchased from Sinopharm Chemical Reagent Co., Ltd. Distilled water was produced by a Milli-Q water purification system (Millipore, Bedford, USA).

\section{Subjects}

This single-center, randomized, single-dose, openlabel, two-period, cross-over study was performed at the Second Affiliated Hospital of Soochow University (Suzhou, China). This study was conducted in accordance with the principles of the Declaration of Helsinki and Good Clinical Practice (GCP) in China. Approval of the study was obtained from the Independent Ethics Committee of the hospital. Written informed consents were obtained from all volunteers prior to the study.

Healthy male Chinese volunteers aged $18-40$ with a body mass index (BMI) $19-24 \mathrm{~kg} / \mathrm{m}^{2}$ and a body weight of more than $50 \mathrm{~kg}$ were eligible for inclusion in the study. Subjects were ascertained to be healthy through medical interview, physical examination, clinical laboratory tests (e.g. haematology, blood chemistry and urinalysis), vital signs and 12-lead ECG within 2 weeks before the first dosing of the study medication.

\section{Study design}

This was a single-center, randomized, single-dose, open-label, two-period, cross-over study. The study comprised a screening period followed by two treatment periods, each separated by a 7-day washout period. Subjects were randomized to one of two treatments: Treatment A, a single $50 \mathrm{mg}$ oral dose of diacerein capsule (Artrodar ${ }^{\circledR}$ ) administered in the fasted state; Treatment B, a single $50 \mathrm{mg}$ oral dose of diacerein capsule $\left(\right.$ Artrodar $\left.^{\circledR}\right)$ administered in the fed state. Treatment B was administered 30 min after starting a high-fat breakfast (856 kcal, protein: $140 \mathrm{kcal}$, carbohydrates: $250 \mathrm{kcal}$, fat: $466 \mathrm{kcal})$. The high-fat breakfast, equivalent to approximately $856 \mathrm{kcal}$, consisted of about $240 \mathrm{~mL}$ of soybean milk, three fried eggs with approximately $35 \mathrm{~g}$ of salad oil, and three pieces of sliced bread. Twenty-four healthy male subjects were randomly selected to receive one of two possible treatment sequences for treatment A or treatment B.

Blood samples ( $4 \mathrm{~mL}$ at each time point) for pharmacokinetic assessments of rhein were collected at the following time points: 0 (predose), $20,40 \mathrm{~min}, 1.0$, $1.5,2.0,2.5,3.0,4.0,5.0,6.0,7.0,8.0,10,12,15$ and 24 $\mathrm{h}$ after drug intake. Blood samples were collected into heparinized vacutainers and centrifuged at $3200 \times \mathrm{g}$ in $4{ }^{\circ} \mathrm{C}$ for $10 \mathrm{~min}$. All of the plasma samples were stored at $-30^{\circ} \mathrm{C}$ until analysis.

\section{Method validation}

Method validation was performed based on the Chinese Pharmacopoeia and Food and Drug Administration (FDA) guideline for industry bioanalytical method validation.

\section{Specificity}

Specificity experiments were carried out using blank human plasma samples from six different sources, to assess potential interference from endogenous compounds.

\section{Calibration curve, QC samples and sensitivity}

Eight-point calibration curves were obtained by spiking blank plasma samples with standard solution at concentrations of $30,100,200,500,1000,2000,5000$, $10000 \mathrm{ng} / \mathrm{mL}$ for rhein. QC samples were prepared at concentrations of $80 \mathrm{ng} / \mathrm{mL}$ (low concentration, LQC), 800 $\mathrm{ng} / \mathrm{mL}$ (medium concentration, MQC) and $8000 \mathrm{ng} / \mathrm{mL}$ (high concentration, HQC). LLOQ (lower limit of quantification), prepared at concentrations of $30 \mathrm{ng} / \mathrm{mL}$, was defined as the lowest point of the calibration curve which fulfilled the requirement of signal-to-noise ratio over 10:1, accuracy within $80-120 \%$ and precision (CV, $\%$ ) lower than $20 \%$. Standard curves, freshly prepared with each run of QC and authentic samples, were generated using a least squares linear regression, with a $1 / x^{2}$ weighting factor in Analyst 1.6 software.

\section{Precision and accuracy}

Accuracy and precision were assayed at LQC, MQC and HQC concentration levels by preparing and analyzing six replicates on three different days. The within-run precision was evaluated by replicate analysis of the QC samples in one run $(n=6)$. The between-run precision was evaluated by replicate analysis of the QC samples in experiments performed on three different days. The precision data are expressed as coefficients of variation (CVs, \%). The accuracy of the assay was expressed by comparing the calculated concentrations of QC samples to their respective nominal values $\times 100 \%$.

\section{Matrix effects}

To assess the matrix effect, LQC, MQC and HQC concentration levels of standard with IS and mobile phase were mixed and mixture was injected into the LC-MS/MS 
system. The blank plasma samples of six different sources were centrifuged and the supernatant were reconstituted with methanol and water containing analyte at the same concentration levels. By calculation the ratio of the areas of rhein and IS spiked into plasma after extraction to the peak areas of the solution with the analyte, the matrix effect (\%) was evaluated.

\section{Stability}

Stability studies were carried out for LQC, MQC and HQC samples under possible conditions that should reflect situations likely to be encountered during actual sample handling and analysis. Long term and short term stability were determined by keeping the samples at $-30^{\circ} \mathrm{C}$ for 47 days and at room temperature for $6 \mathrm{~h}$. Freeze-thaw stability was assessed after three freeze-thaw cycles. In all cases the samples are viewed to be stable if the nominal values obtained are within $\pm 15 \%$ of the back calculated calibration curve concentrations.

\section{Plasma sample analysis}

The concentrations of rhein in plasma samples were determined using the liquid chromatography-tandem mass spectrometry (LC-MS/MS) method developed in our lab. The analytical method for the plasma consisted of the following steps: A $200 \mu \mathrm{L}$ aliquot plasma sample and $10 \mu \mathrm{L}$ methanol was transferred to a $1.5 \mathrm{ml}$ centrifuge tube together with $50 \mu \mathrm{L}$ of internal standard (IS, emodin, $0.5 \mu \mathrm{g} / \mathrm{mL}$ ) working solution in methanol. The sample mixture precipitated with $600 \mu \mathrm{L}$ of methanol. The tubes were then vortex mixed for $1 \mathrm{~min}$ and centrifuged at $15000 \mathrm{rpm}$ for $10 \mathrm{~min}$ at $10{ }^{\circ} \mathrm{C}$, then supernatant was obtained. Finally, $300 \mu \mathrm{L}$ of supernatant was pipetted into an auto sampler vial. Then, $600 \mu \mathrm{L}$ water were added and vortex-mixed for $30 \mathrm{~s} .10 \mu \mathrm{L}$ of mixed solution was injected to LC-MS/MS (API 4000, AB Sciex, Ontario, Canada). The analyte was separated on an ZORBAX Eclipse plus C8 column $(100 \mathrm{~mm} \times 4.6 \mathrm{~mm}$; id, $3.5 \mu \mathrm{m})$ (Agilent, USA) with methanol $-5 \mathrm{mmol} / \mathrm{L}$ ammonium acetate water solution ( $0.4 \%$ formic acid included) $(75: 25, \mathrm{v} / \mathrm{v})$ as the mobile phase and at a flow rate of $1000 \mu \mathrm{L} / \mathrm{min}$ within $8.0 \mathrm{~min}$. The MS/MS was carried out in the negative ionization mode with rhein and emodin (IS) being identified by the multiple reactions monitoring (MRM) at $\mathrm{m} / \mathrm{z} 283.0 \rightarrow 238.8$ and $268.9 \rightarrow 224.8$, respectively. The linear calibration curves of rhein in plasma were obtained over the concentration range of $30-10000 \mathrm{ng} / \mathrm{mL}$. Low-, medium-, and high-quality control plasma samples $(80,800,8000 \mathrm{ng} / \mathrm{mL})$ were analyzed with the study samples to ensure the quality of analysis.

\section{Safety and tolerability evaluation}

Adverse events (AEs), physical examinations, clinical laboratory tests, 12-lead ECGs and vital signs were monitored for safety and tolerability assessment. The relationship of AEs to the study drugs were graded as not related, probably not related, possibly related, probably related or definitely related. All adverse events were coded using the Medical Dictionary for Regulatory Activities $\left(\right.$ MedDRA $\left.^{\circledR}\right)$.

\section{Pharmacokinetic and statistical analysis}

Pharmacokinetic analysis was performed with WinNonlin software (Version 6.3, Pharsight Corporation, Mountain View, CA, USA) utilizing non-compartmental analysis. The maximum plasma concentration $\left(\mathrm{C}_{\max }\right)$ and time to $\mathrm{C}_{\max }\left(\mathrm{t}_{\max }\right)$ were directly obtained from the concentration-time curves. The terminal-phase elimination half-life $\left(t_{1 / 2}\right)$ was calculated as $0.693 / \lambda_{z}$, where $\lambda_{z}$ was the slope of the apparent elimination phase of the natural logarithmic (ln) transformation of the plasma concentration-time curve, which was estimated using liner regression. The area under the plasma concentration-time curve from time zero to $\mathrm{t}\left(\mathrm{AUC}_{0_{-}}\right)$, in which $\mathrm{t}$ is the time of last measurable sample, was calculated according to the linear trapezoidal rule. The AUC from time zero to infinity $\left(\mathrm{AUC}_{0-\infty}\right)$ was estimated as $\mathrm{AUC}_{0-\mathrm{t}}+\mathrm{C}_{\mathrm{t}} / \lambda_{\mathrm{z}}$, in which $\mathrm{C}_{t}$ was the plasma concentration of the last measurable sample. Apparent total clearance $(\mathrm{Cl} / \mathrm{F})$ was calculated as Dose/AUC ${ }_{0-\infty}$ and apparent total volume of distribution $\left(\mathrm{V}_{z} / \mathrm{F}\right)$ as calculated as $\mathrm{CL} / \lambda_{\mathrm{z}}$. The food effect for diacerein capsule $\left(\right.$ Artrodar $^{\circledR}$ ) was derived by applying ANOVAs for $\ln A U C$ and $\operatorname{lnC}_{\max }$ except for $t_{\max }$, for which non-parametric test (NPT) was used.

\section{RESULTS}

\section{Method development}

Chromatograms of different blank plasma showed that no endogenous peak co-eluted with the analyte at the expected retention time. The calibration curves obtained were linear $\left(r^{2} \geq 0.99\right)$ over the concentration range of $30-10000 \mathrm{ng} / \mathrm{mL}$ for rhein. LLOQ was $30 \mathrm{ng} / \mathrm{mL}$ for rhein with a signal to noise ratio $>10$. The intra- and inter-batch precisions for the quality control (QC) samples prepared at the low-, medium-, and high-quality control plasma samples $(80,800,8000 \mathrm{ng} / \mathrm{mL})$ concentrations ranged from $2.1 \%$ to $4.0 \%$ and $6.5 \%$ to $14.9 \%$, respectively. The result of matrix effect for for rhein ranged from $99.1 \%$ 
to $100.1 \%$, suggesting matrix effect by endogenous components was low. In addition, the coefficients of variation $(\mathrm{CVs}, \%)$ of the mean peak areas for rhein in six different plasma were small $(<3.1 \%)$, indicating little difference in ionization efficiency of the analysts from different plasma sources. Rhein was stable at bench-top stability (6 h), repeated freeze-thaw cycles (three cycles), and long-term stability at $-30{ }^{\circ} \mathrm{C}$ for 47 days.

\section{Subjects}

Twenty-four healthy male subjects were enrolled in the study and randomized to 1 of 2 treatments on 2 separate visits. No subject dropped out during the study. Baseline demographics of the study population are presented in Table I.

\section{Pharmacokinetics}

The mean plasma concentration versus time profiles of rhein of the two treatments are shown in Figure 1, and the pharmacokinetic parameters are presented in Table II.

The effect of food intake on the pharmacokinetics of rhein released from diacerein was evaluated. The mean $\mathrm{C}_{\max }$ decreased from 4471 to $3225 \mathrm{ng} / \mathrm{mL}$. The mean $\mathrm{t}_{\max }$ delayed from $2.61 \mathrm{~h}$ in the fasted state to $3.81 \mathrm{~h}$ in the fed state. This seemed consistent with delayed gastric emptying in the fed state. The results showed that the $\mathrm{C}_{\max }$ was lower and occurred later in the fed state than in the fasted state. Therefore, it was concluded that the absorption rate of diacerein was obviously delayed due to food intake.

The mean $\mathrm{AUC}_{0-24 \mathrm{~h}}$ were 24223 and $24316 \mathrm{~h} \cdot \mathrm{ng} / \mathrm{mL}$, and the mean $\mathrm{AUC}_{0-\infty}$ were 24743 and $25170 \mathrm{~h} \cdot \mathrm{ng} / \mathrm{mL}$ in fasted and fed states. These results showed that the extent of absorption was not affected by food intake.

\section{Safety and tolerability}

The number of subjects experiencing at least one AE was $1(4.17 \%)$ of 24 for diacerein capsule $\left(\right.$ Artrodar $\left.^{\circledR}\right)$ as shown in Table III. The occurring AEs in the groups were accelerated intestinal transit. The AEs were assessed to be possibly related to investigational drugs.

Diacerein was safe and well tolerated, and all subjects were in good compliance. All reported AEs were mild or moderate in intensity and there were no SAEs, deaths or withdrawals.

\section{DISCUSSION}

The objective of this study was to evaluate the effects

TABLE I - Summary of demographic data ${ }^{\mathrm{a}}$

\begin{tabular}{ccccc}
\hline Number $(\mathbf{n})$ & Age $(\mathbf{y})$ & Bodyweight $\mathbf{( k g )}$ & Height $(\mathbf{c m})$ & BMI $\left(\mathbf{k g} / \mathbf{m}^{2}\right)$ \\
\hline 24 & $24 \pm 3$ & $61.9 \pm 6.9$ & $169.8 \pm 5.6$ & $21.4 \pm 1.5$ \\
\hline
\end{tabular}

${ }^{a}$ Data are mean \pm SD unless stated otherwise; $\mathrm{BMI}=$ body mass index; $\mathrm{SD}=$ standard deviation.

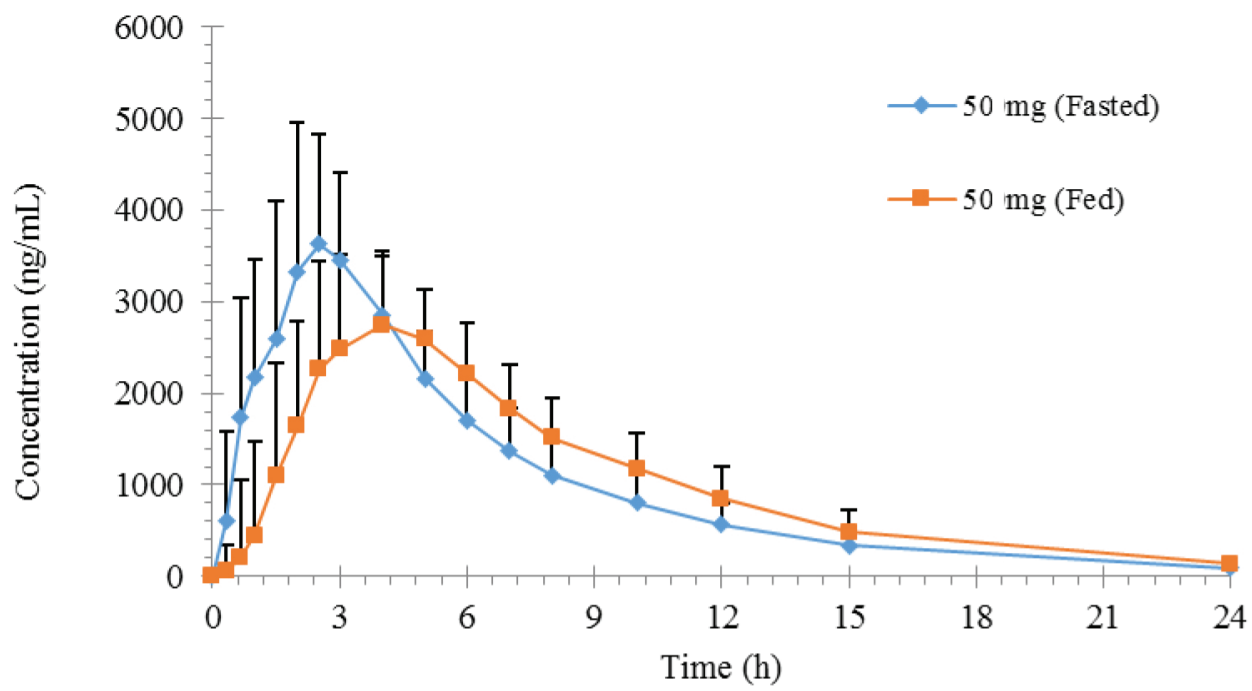

FIGURE 1 - Mean plasma concentration-time curves of rhein after oral administration of 50 mg dose of diacerein capsule (Artrodar ${ }^{\mathbb{R}}$ ) in fed state or fasted state. Data are represented as mean \pm standard error of the mean. 
TABLE II - Main pharmacokinetic parameters of rhein after oral administration of $50 \mathrm{mg}$ dose of diacerein capsule (Artrodar $\left.{ }^{\circledR}\right)$ in fed state or fasted state

\begin{tabular}{lcc}
\hline Parameter & $\begin{array}{c}\text { Oral administration of diacerein capsule } \\
\left(\text { Artrodar }^{\circledR} \text { ) in fed state }\right.\end{array}$ & $\begin{array}{c}\text { Oral administration of diacerein capsule } \\
\text { (Artrodar }^{\circledR} \text { in fasted state }\end{array}$ \\
\hline$C_{\max }\left(\mathrm{ng} \cdot \mathrm{mL}^{-1}\right)$ & $3225 \pm 755$ & $4471 \pm 936$ \\
$\mathrm{t}_{\max }(\mathrm{h})$ & $4.00(1.50-7.00)$ & $2.50(0.67-6.00)$ \\
$\mathrm{AUC}_{0-24 \mathrm{~h}}\left(\mathrm{ng} \cdot \mathrm{mL}^{-1} \cdot \mathrm{h}\right)$ & $24316 \pm 5856$ & $24223 \pm 4895$ \\
$\mathrm{AUC}_{0-\infty}\left(\mathrm{ng} \cdot \mathrm{mL}^{-1} \cdot \mathrm{h}\right)$ & $25170 \pm 6415$ & $24743 \pm 5046$ \\
$t_{1 / 2}(\mathrm{~h})$ & $4.19 \pm 1.05$ & $4.22 \pm 0.42$ \\
$V_{\mathrm{z} /} \mathrm{F}(\mathrm{L})$ & $12.30 \pm 2.73$ & $12.68 \pm 2.29$ \\
$\mathrm{CL} / \mathrm{F}\left(\mathrm{L} \cdot \mathrm{h}^{-1}\right)$ & $2.113 \pm 0.532$ & $2.101 \pm 0.419$ \\
\hline
\end{tabular}

aPharmacokinetic data are presented as mean $\pm \mathrm{SD}$, except for $\mathrm{t}_{\max }$, which is shown as median (range).

TABLE III - Incidence of adverse events (AEs)

\begin{tabular}{|c|c|c|}
\hline \multirow[t]{2}{*}{ Variable } & \multicolumn{2}{|c|}{$\begin{array}{c}\text { diacerein capsule } \\
\left(\text { Artrodar }^{\circledR}\right)(50 \mathrm{mg})\end{array}$} \\
\hline & fed & fasted \\
\hline $\mathrm{n}$ & 24 & 24 \\
\hline Participants with $\geq 1 \mathrm{AE}[\mathrm{n}(\%)]$ & 0 & $1(4.17)$ \\
\hline \multicolumn{3}{|l|}{ AEs } \\
\hline accelerated intestinal transit & 0 & $1(4.17)$ \\
\hline
\end{tabular}

of food on the pharmacokinetics of rhein released from diacerein in healthy Chinese subjects, and this is the first report of its kind.

In this study, $\mathrm{C}_{\max }$ was lower and occurred later in the fed state compared to the fasted state, but the AUC was less affected by food intake. There was a significant difference in $\mathrm{C}_{\max }$ and $\mathrm{t}_{\max }$ between the fasted and fed states. However, the AUC and $t_{1 / 2}$ of rhein released from diacerein showed no significant differences between the fasted and fed states. Therefore, it was concluded that the absorption rate of diacerein capsule (Artrodar ${ }^{\circledR}$ ) was obviously delayed by food intake but the absorption degree remained unaffected.

So far, Mandawgade et al. (2016) reported that the $\mathrm{AUC}_{0-\infty}$ and $\mathrm{C}_{\max }$ of a $50 \mathrm{mg}$ dose of diacerein capsule in the fasted state were $26578.63 \mathrm{~h} \cdot \mathrm{ng} / \mathrm{mL}$ and $4298.63 \mathrm{ng} / \mathrm{mL}$. However, Chakrabarty US (Chakrabarty et al., 2008) reported that the $\mathrm{AUC}_{0-\infty}$ and $\mathrm{C}_{\max }$ of a $50 \mathrm{mg}$ dose of diacerein capsule in the fasted state were $22380 \pm 3607 \mathrm{~h} \cdot \mathrm{ng} / \mathrm{mL}$ and $3270 \pm 333 \mathrm{ng} / \mathrm{mL}$. Nicolas $\mathrm{P}$ (Nicolas et al., 1998) reported that the $\mathrm{AUC}_{0-\infty}$ of a $50 \mathrm{mg}$ dose of diacerein capsule $\left(\right.$ Artrodar $\left.^{\mathbb{B}}\right)$ in the fasted state and in fed state were $20900 \mathrm{~h} \cdot \mathrm{ng} / \mathrm{mL}$ and $25900 \mathrm{~h} \cdot \mathrm{ng} / \mathrm{mL}$. The $\mathrm{t}_{\max }$ increased from 2.4 to $5.2 \mathrm{~h}$. In this study, the $\mathrm{AUC}_{0-\infty}$ and $\mathrm{C}_{\max }$ of a $50 \mathrm{mg}$ dose of diacerein capsule $\left(\right.$ Artrodar $\left.^{\circledR}\right)$ in the fasted and fed state were $24743 \pm 5046 \mathrm{~h} \cdot \mathrm{ng} / \mathrm{mL}$ and $4471 \pm 936 \mathrm{ng} / \mathrm{mL}$, $25170 \pm 6415 \mathrm{~h} \cdot \mathrm{ng} / \mathrm{mL}$ and $3225 \pm 755 \mathrm{ng} / \mathrm{mL}$, respectively. The difference between us and Chakrabarty US (Chakrabarty et al., 2008) may be due to the sample size, subject variability, and period effects.

Food could retard gastric emptying, delay the delivery of the drug to the intestinal absorption sites, resulting in delayed and reduced peak plasma concentration of rhein. However, the AUC and elimination of rhein was less affected by food intake. Nicolas P (Nicolas et al., 1998 ) reported that a significant $24 \%$ increase in $\mathrm{AUC}_{0-}$ $\infty$ was also observed (from $20.9 \mathrm{~h} \cdot \mu \mathrm{g} / \mathrm{mL}$ in the fasting state to $25.9 \mathrm{~h} \cdot \mu \mathrm{g} / \mathrm{mL}$ with a meal. Based on these data, it is advisable to take diacerein with meals, in order to maximize its absorption. In this study, when diacerein was taken with food, no statistically significant changes were observed in the AUC of rhein in comparison to the fasting state. However, as diacerein may cause acceleration of the intestinal transit time, it appears logical to recommend the administration of diacerein with meals.

In this study, accelerated intestinal transit was assessed by the investigators to be possibly related to investigational drugs. There were no significant clinical findings in hematology tests, urine tests, or 12-lead ECGs regarding the safety assessment of the study subjects during the study period. All results were within normal ranges. Vital signs, including blood pressure, pulse rate and body temperature, and the physical examination results showed no clinically significant changes. There was no SAEs, death or withdrawal.

\section{CONCLUSIONS}

This study demonstrated the effects of on the 
pharmacokinetics of diacerein capsule $\left(\operatorname{Artrodar}^{\circledR}\right)$ in healthy Chinese male subjects. The absorption rate of diacerein capsule (Artrodar ${ }^{\circledR}$ ) was obviously delayed by food intake but the absorption degree remained unaffected.

\section{ACKNOWLEDGMENTS}

The authors thank all of the subjects enrolled in this study. We also thank the staff of the clinical ward and bioanalytical lab of Clinical pharmacology laboratory in the Second Affiliated Hospital of Soochow University (Suzhou, China).

\section{CONFLICT OF INTEREST}

The authors state no conflict of interest in relation to the present study.

\section{REFERENCES}

Chakrabarty US, Mandal U, Bhaumik U, Chatterjee B, Ghosh A, Bose A, et al. Bioequivalence study of two capsule formulations containing diacerein $50 \mathrm{mg}$ in healthy human subjects. Arzneimittelforschung. 2008;58(8):405-09.
Debord P, Louchahi K, Tod M, Molinier P, Berdah L, Perret $\mathrm{G}$, et al. Influence of renal function on the pharmacokinetics of diacerein after a single oral dose. Fundam Clin Pharmacol. 1993;7(8):435-41.

Debord P, Louchahi K, Tod M, Cournot A, Perret G, Petitjean O. Influence of renal function on the pharmacokinetics of diacerein after a single oral dose. Eur J Drug Metab Pharmacokinet. 1994;19(1):13-9.

Mandawgade SD, Kulkarni S, Pal A, Srivastava S, Padhi BK, Raghuvanshi RS. Development and pharmacokinetic evaluation of new oral formulations of diacerein. Curr Drug Deliv. 2016;13(1):83-89.

Nicolas P, Tod M, Padoin C, Petitjean O. Clinical pharmacokinetics of diacerein. Clin Pharmacokinet. 1998;35(5):347-59.

Received for publication on $22^{\text {nd }}$ January 2018 Accepted for publication on $12^{\text {th }}$ June 2018 